\title{
Influence of Socioeconomic Status on Caries Prevalence in Chennai Population: A Cross-sectional Study
}

\author{
${ }^{1}$ Veni Ashok Baskaran, ${ }^{2}$ Gopal Shankarnarayan, ${ }^{3}$ Meenakshisundaram Rajasekaran, ${ }^{4}$ Rashmi, ${ }^{5}$ Saravanan Poorni
}

${ }^{6}$ Manali R Srinivasan

\begin{abstract}
Aim: The aim of the present study is to evaluate the influence of socioeconomic status and social habits on the prevalence of dental caries in Chennai population. Cross sectional study was conducted in 500 patients by survey method using a questionnaire. Data was collected based on demographic details, information on the income, educational qualification, occupation, social habits (tobacco and alcohol consumption) and the caries exposure in terms of presence or absence of dental caries or a restoration. The data was tabulated using Microsoft Excel and statistically analysed using SPSS version $22.91 .8 \%$ of subjects in the lower socio economic status have a caries exposure while only $82 \%$ and $73.4 \%$ of the medium and higher economic status had caries. Within the limitations of the present study it can be concluded that there exists a connection between the individuals socio economic condition and the oral health status that calls for implementation of oral health programs.
\end{abstract}

Keywords: Caries prevalence, Socioeconomic status, Tobacco users and dental caries.

How to cite this article: Baskaran VA, Shankarnarayan G, Rajasekaran M, Rashmi, Poorni S, Srinivasan MR. Influence of Socioeconomic Status on Caries Prevalence in Chennai Population: A Cross-sectional Study. J Oper Dent Endod 2017;2(1):15-18.

Source of support: Nil

Conflict of interest: None

\section{INTRODUCTION}

Oral health is a vital part of general well-being. Despite enormous efforts to enhance oral health on a global scale, dental caries and periodontal disease continue to plague many populations around the world. ${ }^{1}$ Dental caries is a multifactorial disease. Dental caries is a crippling affliction of the oral cavity. The pathogenesis is complex involving many contributing factors. Apart from diet,

\footnotetext{
${ }^{1,3}$ Professor, ${ }^{2,5}$ Reader, ${ }^{4}$ Student, ${ }^{6}$ Professor and Head

1,2Department of Conservative Dentistry and Endodontics, Ragas Dental College and Hospital, Chennai, Tamil Nadu, India

${ }^{3}$ Department of Conservative Dentistry and Endodontics, Ragas Dental College and Hospital, Chennai, Tamil Nadu, India

${ }^{4}$ Sri Venkateswara Dental College and Hospital, Chennai, Tamil Nadu, India

${ }^{5,6}$ Department of Conservative Dentistry and Endodontics Sri Venkateswara Dental College and Hospital, Chennai, Tamil Nadu, India
}

Corresponding Author: Veni Ashok Baskaran, Professor Department of Conservative Dentistry and Endodontics, Ragas Dental College and Hospital, Chennai, Tamil Nadu, India, Phone: +914424530001, e-mail: ashokbaskaran@gmail.com oral flora, and morphology of the tooth, an array of risk factors-both local and general-have been implicated. ${ }^{2}$ Gender, socioeconomic status (SES), oral hygiene, and social habits like alcohol consumption and use of tobacco products may be key determinants in disease progress. ${ }^{3-19}$ Though the extent to which each of these factors can influence the disease process has been analyzed earlier individually, the impact of SES in our population is still not much explored.

Socioeconomic status is generally measured by indicators of human capital, such as social class, wealth, education and individual income, and educational and occupational prestige. Income, education, and occupation, the three mysterious determinants of health, are not likely to have a direct effect but serve as proxies for other determinants. Hence, what appears to be a direct impact of SES inequality may instead be operating through differential exposure to conditions that have more immediate effects on health. This includes health care, environmental exposure, behavior, and lifestyle. ${ }^{13}$

Cross-sectional studies will help us in exploring the association of various factors with the disease and also to understand the preventive strategies that should be undertaken in the control of a disease. ${ }^{3}$ This will also aid in assessing the treatment needs and suggesting the modes of intervention. Literature reveals a number of prevalence studies on dental caries done in different parts of the country. ${ }^{20-23}$ There was a paucity in the literature regarding the association of SES on the prevalence of dental caries in Chennai population. ${ }^{24}$ Taking into consideration the public health significance of dental caries, this study was undertaken to estimate the magnitude of impact of SES and social factors on the disease prevalence. Thus, the aim of this study is to evaluate the influence of SES and social habits on the prevalence of dental caries in Chennai population.

\section{MATERIALS AND METHODS}

The cross-sectional study was conducted in Chennai population. The survey was conducted between March 2013 and March 2014. After obtaining the ethical clearance from the Institution's Review Board of Ragas Dental College and Hospital, patients visiting the outpatient department were recruited. The nature of the survey and the objectives were explained to the patients. They were assured of the confidentiality regarding the information. Informed 
consent was obtained from the patients. Essential treatment was provided after the assessments were completed.

The study population comprised 500 patients who were attending the outpatient department of the hospital. A pilot study was done and the sample size was calculated based on the results of the pilot study.

A survey form was prepared to record the demographic details, information on the income, educational qualification, occupation, social habits (tobacco and alcohol consumption), and the caries exposure in terms of presence or absence of dental caries or a restoration.

The data were collected by a single operator. Prior to the initiation of the survey, the investigator was trained to comprehend the assessments. The investigator strictly adhered to personal protective barrier protocol. All examinations were done under illumination using a sterile mouth mirror and explorer. Only definite cavitations of the tooth surface were recorded as dental caries to reduce examiner confusion regarding diagnosis and exclusion of intact demineralized (white spot) lesions.

The data were tabulated using Microsoft Excel and statistically analyzed using Statistical Package for the Social Sciences version 22.

\section{RESULTS}

The study population comprised 500 patients in the age group of 15 to 73 years. Among the study participants, 217 were males and 283 were females. Table 1 shows the caries prevalence according to SES, where $91.8 \%$ of subjects in the lower SES have a caries exposure, while only 82 and $73.4 \%$ of the medium and higher economic status respectively, had caries. Tables 2 and 3 show

Table 1: Caries prevalence according to SES

\begin{tabular}{llll}
\hline SES & Number & Affected & Percentage \\
\hline Low & 183 & 168 & 91.8 \\
Medium & 223 & 183 & 82 \\
High & 94 & 69 & 73.4 \\
p-value & $<0.001$ & & \\
\hline
\end{tabular}

Table 2: Comparison of proportion of caries affected subjects among the alcohol users

\begin{tabular}{llll}
\hline Alcohol usage & Caries present & Caries absent & Total \\
\hline Habit present & $134(73 \%)$ & 49 & 183 \\
Habit absent & $261(81 \%)$ & 56 & 317 \\
\hline Total & 395 & 105 & 500 \\
\hline
\end{tabular}

Table 3: Comparison of proportion of caries affected subjects among the tobacco users

\begin{tabular}{llll}
\hline Tobacco usage & Caries present & Caries absent & Total \\
\hline Habit present & $132(75 \%)$ & 44 & 176 \\
Habit absent & $234(72 \%)$ & 90 & 324 \\
\hline Total & 366 & 134 & 500 \\
\hline
\end{tabular}

comparison of proportion of caries affected subjects among the alcohol and tobacco users. A total of $134 \mathrm{sub}-$ jects $(73 \%)$ of alcohol users had a caries exposure, while $261(81 \%)$ of nonalcohol consumers had caries. Among the tobacco users, 132 (75\%) were affected, while 234 (72\%) among the nontobacco consumers were affected. Chi-square analysis of the data collected showed that the difference in the caries prevalence among the various categories of SES was statistically significant.

\section{DISCUSSION}

Dental caries is the microbiologic disease of the calcified tissues of the teeth characterized by the demineralization of the inorganic portion and destruction of the organic portion of the tooth. The sequel of deterioration can cause morbid changes to the oral health and the general health. ${ }^{25}$ In developing countries like India, the attention deserved by oral health is not being met by a clear majority of the population. Dental caries cannot be viewed as the disease of the oral cavity alone. The association of several sociodemographic factors with any disease process is inevitable. ${ }^{26}$

Socioeconomic status is associated with a wide range of health-related issues. The gap between the health "haves" and the "have-nots" is exaggerated by the disparities in these components. Addressing the pathway by which the components of SES affect oral health is of primordial importance. Identification of this enables for better treatment options. Income, occupation, and education are traditionally regarded as the components of SES. ${ }^{20}$

Education determines the occupational opportunities and the earning potential. There is easy access to health information and health-promoting resources. ${ }^{27}$ Literature has examined years of completed study on the significant association of education and SES. ${ }^{28}$ At lower incomes, the relation between health and income is stronger. There is persistence of health effects above the poverty level. Effects of health, at the upper part of distribution, are reflective of a relative status, while at the lower part the association is linked to complete deprivation. ${ }^{29}$ Occupational status is a more complex variable. ${ }^{30}$

Though income, education, and occupation are the three traditional components of SES, they may not have a direct effect and operate through differential components, such as environmental exposure, behavior, and lifestyle. ${ }^{31,32}$ The greatest behavioral risk is tobacco and alcohol use. ${ }^{33}$ Hence, in addition to the income, education, and occupation, use of alcohol and tobacco and its impact on caries prevalence was studied.

Based on the results of the current study, there exists an inverse relationship between the prevalence of dental caries and SES. Those with less education and less income are more likely to smoke. Smoking prevalence reflects 
the likelihood of initiating smoking as well as of quitting. Winkleby et $\mathrm{al}^{34}$ found that neither education nor income was associated with smoking onset. However, the more educated were more likely to try to quit, and among those who tried to quit, those with higher incomes were more likely to succeed. This suggests that efforts to encourage quitting need to be geared more strongly to those with less education and that the means of quitting need to be made more accessible to the poor. Higher taxes on cigarettes, resulting in higher prices, can reduce consumption. However, this increases the economic burden on low-income smokers, who are more likely to lack resources to get help in quitting. If taxation policies are used, these need to be coupled with more positive approaches to aid in smoking cessation. ${ }^{35}$ Use of tobacco in any form appears to substantially increase the risk for dental caries. ${ }^{36-38}$ Patterns of alcohol use by SES are more complex, as are the health risks related to alcohol. Moderate drinking does not show an SES gradient, while heavy drinking is more common at lower SES levels. ${ }^{39}$

The results of the present study show that the caries prevalence was higher among the nonalcohol and tobacco users. Alcohol has been thought to influence dental caries via the microbial oxidation of ethanol in saliva in alcohol abusers, resulting in the formation of acetaldehyde that inhibits the cariogenic oral flora. Alcohol enhances fluoride release from certain restorative materials. ${ }^{40}$ Nicotine, a major constituent of tobacco, is known to limit the proliferation of Streptococcus viridans. ${ }^{41}$ On the contrary, sugar-laced chewing tobacco extracts have been shown by in vitro evidence for stimulated growth of Streptococcus mutans and Streptococcus sanguis. ${ }^{42}$ It is considered that frequent chewing of arecanut confers a protection against dental caries. Arecanut by itself lacks ingredients that have cariostatic properties. The extrinsic stain formed by the chronic habit acts as a laminate, preventing adherence and colonization of the cariogenic microbes. The gritty consistency of the arecanut mediates a mechanical cleansing activity eliminating the food debris. ${ }^{43}$ Repeated chewing stimulus results in an increased salivary flow rate that also aids in the removal of organisms and food debris. The tannins in this bolus have antimicrobial properties. Attrition in chewers makes the teeth surface smooth and reduces the risk of pit and fissure caries. The sclerosis of dentin by repeated masticatory trauma renders the dentin resistant to the microbial invasion. ${ }^{44}$ The addition of lime alters the $\mathrm{pH}$ of the oral cavity, making it unsuitable for the cariogenic organisms to survive. Moreover, the salivary flow rate and $\mathrm{pH}$ have been shown to vary with the type of arecanut and tobacco chewed. Attrition with the use of chewing tobacco and presence of extrinsic stains with tobacco use appear to provide a protective effect from caries. ${ }^{45}$ The changes in oral microflora owing to tobacco use and alcohol may play a critical role in the initiation and progression of dental caries. It is still unclear how different use of psychoactive substances influences the overall dental caries experience in the Chennai population.

\section{CONCLUSION}

Within the limitations of the present study, it can be concluded that there exists a connection between the individuals' socioeconomic condition and the oral health status that calls for implementation of oral health programs. Individual's habits like tobacco and alcohol do have an influence on caries prevalence, though further studies are required to obtain a clear association.

\section{REFERENCES}

1. CAPP country profile [Internet]. Available from: http://www. whocollab.od.mah.se/searo/india/indiacar.html cited on 18.11.2016.

2. Dash JK, Sahoo PK, Bhuyan SK, Sahoo SK. Prevalence of dental caries and treatment needs among children of Cuttack (Orissa). J Indian Soc Pedod Prev Dent 2002 Dec;20(4):139-143.

3. Willershausen B, Witzel S, Schuster S, Kasaj A. Influence of gender and social factors on oral health, treatment degree and choice of dental restorative materials in patients from a dental school. Int J Dent Hyg 2010 May;8(2):116-120.

4. Lukacs JR, Largaespada LL. Explaining sex differences in dental caries prevalence: saliva, hormones, and "life-history" etiologies. Am J Hum Biol 2006 Jul-Aug;18(4):540-555.

5. Moynihan P, Petersen PE. Diet, nutrition and the prevention of dental diseases. Public Health Nutr 2004 Feb;7(1A):201-226.

6. Bruno-Ambrosius K, Swanholm G, Twetman S. Eating habits, smoking and toothbrushing in relation to dental caries: a 3-year study in Swedish female teenagers. Int J Paediatr Dent 2005 May;15(3):190-196.

7. Chatterjee M, Bandyopadhyay AR. A study on nutritional status and dental caries in permanent teeth among school going girl of Bengalee population, India. Adv Anthropol 2012 Aug;2(3):112-116.

8. Joyson M, Rangeeth BN, Deepa G. Prevalence of dental caries, socio-economic status and treatment needs among 5 to 15 year old school going children of Chidambaram. J Clin Diagn Res 2011 Feb;5(1):146-151.

9. Bansal R, Sharma S, Shukla AK, Parashar P, Singh D, Mohan A, Varshney SA. Prevalence of dental caries among school children in Meerut. Asian Pac J Health Sci 2015;2(1):84-88.

10. Rooban T, Vidya K, Joshua E, Rao A, Ranganathan S, Rao UK, Ranganathan K. Tooth decay in alcohol and tobacco abusers. J Oral Maxillofac Pathol 2011 Jan;15(1):14-21.

11. Adler NE, Newman K. Socioeconomic disparities in health: pathways and policies. Health Aff (Millwood) 2002 MarApr;21(2):60-76.

12. Elfaki NK, Brair SL, Aedh A. Influence of socioeconomic status on dental health among primary school children in Najran. IOSR JDMS 2015;14(8):54-57.

13. Popoola BO, Denloye OO, Iyun OI. Influence of parental socioeconomic status on caries prevalence among children seen at the University College Hospital, Ibadan. Ann Ib Postgrad Med 2013 Dec;11(2):81-86. 
14. Borrell LN. Alcohol consumption was adversely associated with dental caries but not periodontal disease in a Swedish study. J Evid Based Dent Pract 2009 Mar;9(1):40-41.

15. Mäkinen KK, Bennett CA, Hujoel PP, Isokangas PJ, Isotupa KP, Pape HR Jr, Mäkinen PL. Xylitol chewing gums and caries rates: a 40-month cohort study. J Dent Res 1995 Dec;74(12): 1904-1913.

16. Heng CK, Badner VM, Freeman KD. Relationship of cigarette smoking to dental caries in a population of female inmates. J Correct Health Care 2006 Jul;12(3):164-174.

17. Deshpande A, Jadad AR. The impact of polyol-containing chewing gums on dental caries: a systematic review of original randomized controlled trials and observational studies. J Am Dent Assoc 2008 Dec;139(12):1602-1614.

18. Holmén A, Strömberg U, Magnusson K, Twetman S. Tobacco use and caries risk among adolescents - a longitudinal study in Sweden. BMC Oral Health 2013 Jul;13:31.

19. Vellappally S, Fiala Z, Smejkalová J, Jacob V, Shriharsha P. Influence of tobacco use in dental caries development. Cent Eur J Public Health 2007 Sep;15(3):116-121.

20. Singh G, Kaur G, Mengi V, Singh B. A study of dental caries among school children in rural area of Jammu. Ann Dent Res 2014;2(1):1-5

21. Shubha $P$, Chandan CS. Prevalence of dental caries among Chennai population. J Pharm Sci Res 2015;7(10):895-896.

22. Rajesh SS, Venkatesh P. Prevalence of dental caries among school-going children in South India. J Med Sci Public Health 2016;5(4):700-704.

23. Kotecha PV, Patel SV, Bhalani KD, Shah D, Shah VS, Mehta KG. Prevalence of dental fluorosis and dental caries in association with high levels of drinking water fluoride content in a district of Gujarat, India. Indian J Med Res 2012 Jun;135(6):873-877.

24. Prakash, H.; Duggal, R.; Mathur, VP.; Petersen, PE. Manual for multicentric oral health survey. India: DGHS, MoHFW, GOI, WHO; 2004-2005.

25. Chakraborty M, Saha JB, Bhattacharya RN, Roy A, Ram R. Epidemiological correlates of dental caries in an urban slum of West Bengal. Indian J Pub Health 1997 Apr-Jun;41(2): 56-60.

26. Link BG, Phelan J. Social conditions as fundamental causes of disease. J Health Soc Behav 1995; Spec No:80-94.

27. Ross $\mathrm{CE}, \mathrm{Wu} \mathrm{CL}$. The links between education and health Am Soc Rev 1995 Oct;60(5):719-745.

28. Keating D, Hertzman C. Developmental health and the wealth of nations: social, biological and educational dynamics. Can Child Adolesc Psychiatr Rev 2003;12(1):26-27.

29. Backlund E, Sorlie PD, Johnson NJ. A comparison of the relationships of education and income with mortality: the
National Longitudinal Mortality Study. Soc Sci Med 1999 Nov;49(10):1373-1384.

30. Ross CE, Mirowsky J. Does employment affect health? J Health Soc Behav 1995 Sep;36(3):230-243.

31. Angell M. Privilege and health - what is the connection. N Engl J Med 1993 Jul;329(2):126-127.

32. Lalonde, M. A new perspective on the health of Canadians. Government of Canada Report. Ottawa: Minister of Supply and Services Canada; 1981.

33. Pierce JP, Fiore MC, Novotny TE, Hatziandreu EJ, Davis RM. Trends in cigarette smoking in the United States. Educational differences are increasing. JAMA 1989 Jan;261(1):56-60.

34. Winkleby MA, Cubbin C, Ahn DK, Kraemer HC. Pathways by which SES and ethnicity influence cardiovascular disease risk factors. Ann N Y Acad Sci 1999;896:191-209.

35. Chaloupka, F.; Warner, F. The economics of smoking. NBER; 1999.

36. Thavarajah R, Rao A, Raman U, Rajasekaran ST, Joshua E, Hemalatha R, Kannan R. Oral lesions of 500 habitual psychoactive substance users in Chennai, India. Arch Oral Biol 2006 Jun;51(6):512-519.

37. Rooban T, Rao A, Joshua E, Ranganathan K. Dental and oral health status in drug abusers in Chennai, India: a cross sectional study. J Oral Maxillofac Pathol 2008 Jan;12(1):16-21.

38. Rooban T, Rao A, Joshua E, Ranganathan K. The prevalence of oral mucosal lesions in alcohol misusers in Chennai, south India. Indian J Dent Res 2009 Jan-Mar;20(1):41-46.

39. Pamuket E, Makuc D, Heck K, Reuben C, Lochner K. Socioeconomic Status and Health Chartbook. Health, United Staes, 1998 Hyattsville, Maryland National centre for Health Statistics.

40. Dasanayake AP, Warnakulasuriya S, Harris CK, Cooper DJ, Peters TJ, Gelbier S. Tooth decay in alcohol abusers compared to alcohol and drug abusers. Int J Dent 2010;2010:786503.

41. Pavia CS, Pierre A, Nowakowski J. Antimicrobial activity of nicotine against a spectrum of bacterial and fungal pathogens. J Med Microbiol 2000 Jul;49(7):675-676.

42. Lindemeyer RG, Baum RH, Hsu SC, Going RE. In vitro effect of tobacco on the growth of oral cariogenic streptococci. J Am Dent Assoc 1981 Nov;103(5):719-722.

43. Trivedy CR, Craig G, Warnakulasuriya S. The oral health consequences of chewing areca nut. Addict Biol 2002 Jan;7(1): 115-125.

44. Möller IJ, Pindborg JJ, Effendi I. The relation between betel chewing and dental caries. Scand J Dent Res 1977 Jan;85(1): 64-70.

45. Rooban T,Mishra G, Elizabeth J, Ranganathan K, Saraswathi TR. Effect of habitual arecanut chewing on resting whole mouth salivary flow rate and pH. Indian J Med Sci 2006 Mar;60(3):95-105. 